\title{
Diagnostic and therapeutic role of microRNAs in oral cancer (Review)
}

\author{
JING WANG, NAJUN LV, XINXIN LU, RONGTAO YUAN, ZHENGGANG CHEN and JIANGBO YU \\ Oral Research Center, Qingdao Municipal Hospital, Qingdao, Shandong 266011, P.R. China
}

Received July 22, 2020; Accepted October 27, 2020

DOI: $10.3892 /$ or.2020.7854

\begin{abstract}
Oral cancer is one of the leading types of cancer and remains the most common cause of cancer-related mortality in Asia. The pathogenesis of oral cancer is complicated and, due to lack of accurate diagnostic methods and efficient treatment strategies, oral cancer is responsible for a large number of deaths. Therefore, there is an urgent need for developing novel diagnostic tools and targeted therapies. MicroRNAs (miRNAs) represent a class of small non-coding RNAs that are key elements and play critical regulatory roles in the pathological processes of various diseases. miRNAs are widely distributed in body fluids and are specifically expressed in different cancers, and they may represent effective biomarkers that may be used for early detection of oral cancer. In addition, miRNAs are involved in oral cancer development, progression and prognosis by targeting a broad range of mRNAs that may
\end{abstract}

Correspondence to: Jiangbo Yu, Oral Research Center, Qingdao Municipal Hospital, 5 Donghaizhong Road, Qingdao, Shandong 266011, P.R. China

E-mail: jbyu0532@126.com

Abbreviations: OSCC, oral squamous cell carcinoma; ROC, receiver operating characteristics; AUC, area under the curve; mTOR, mammalian target of rapamycin; AKT, protein kinase B; UBE2B, ubiquitin-conjugating enzyme E2B; SOX12, SRY-box transcription factor 12; FGF1, fibroblast growth factor 2; NR4A1/Nur77, nuclear receptor subfamily 4 group A member 1 ; Foxo3a/p $27^{\text {Kipl }}$, forkhead box O3A/cyclin-dependent kinase inhibitor 1B; HIP1, Huntingtin-interacting protein 1; GIT1, GPCR kinase 2 interacting protein 1; LATS2, large tumor suppressor kinase 2; PER1, period 1 gene; ACOX1, acyl-CoA oxidase 1; HBp17, heparin-binding protein 17; ARID2, AT-rich interaction domain 2; GLUT1, glucose transporter 1; TMEM182, transmembrane protein 182; CDH1, E-cadherin gene 1; RGMA, repulsive guidance molecule A; RIG-I, retinoic acid-inducible gene-I; TNF- $\alpha$, tumor necrosis factor- $\alpha$; ROR $\alpha$, retinoic acid receptor-related orphan receptor $\alpha$; BIN1, bridging integrator 1; AXL, receptor tyrosine kinase; PDCD7, programmed cell death 7; Bmi-1, B-cell-specific Moloney murine leukemia virus integration site 1; BIRC3, baculoviral IAP repeat-containing 3; FAP, fibroblast activation protein; DENND2D, differentially expressed in normal cells and neoplasia domain containing $2 \mathrm{D}$; TGFBR 1 , TGF- $\beta$ receptor 1

Key words: microRNAs, oral cancer, biomarker, target therapy be of therapeutic value for oral cancer. The aim of the present review was to summarize the role of miRNAs as new diagnostic tools and potential therapeutic targets in oral cancer, and investigate the underlying molecular mechanisms.

\section{Contents}

1. Introduction

2. Expression profile of miRNAs in oral cancer

3. Therapeutic effects of miRNAs in oral cancer

4. Discussion and outlook

\section{Introduction}

Oral cancer is a type of head and neck cancer and its main subtype is oral squamous cell carcinoma (OSCC) (1). OSCC occurs in the oral cavity, which includes the tongue, floor of the mouth, buccal mucosa and alveolar rim (2). OSCC presents a major global health concern, with an estimated $>300,000$ cases per annum (3) and $\sim 1.8$ million deaths (4). Currently, the diagnosis and treatment of OSCC represent a clinical challenge.

miRNAs are a class of small non-coding RNAs that are involved in the regulation of a variety of physiological processes by targeting specific mRNAs (5). miRNAs have been reported to play an important regulatory role in cancer occurrence and progression (6), and they may be of value as targets in oral cancer treatment (7). Due to their stability in human peripheral blood and body fluids and disease-specific expression, an increasing number of studies indicate that miRNAs may represent an ideal set of biomarkers applied in early diagnosis and prognosis of cancers (8).

The focus of the present review was the detailed regulatory role of miRNAs in oral cancer and their value in diagnosis and treatment. The conclusions of this review may contribute to the early diagnosis and targeted therapy of oral cancer.

\section{Expression profile of miRNAs in oral cancer}

miRNAs are a family of short, single-stranded, small non-coding RNAs, containing 20-22 nucleotides (9). The miRNA expression profiles and levels differ between patients with cancer and healthy individuals, and they are implicated 
in human carcinogenesis $(10,11)$. According to their chemical and structural properties, circulating miRNAs are stable in the serum, plasma and other body fluids (8), and they may be considered as potential clinical diagnostic and prognostic biomarkers.

miRNAs may be novel diagnostic biomarkers in oral cancer. The occurrence of oral cancer is multifactorial, and is accompanied by genetic and epigenetic instability (12). With the widespread application of next-generation sequencing, a growing number of studies have demonstrated that certain miRNAs are differentially expressed in oral cancer. In addition, the results of receiver operating characteristic (ROC) curve and area under the curve (AUC) analysis have indicated that the differentially expressed miRNAs may help distinguish patients with oral cancer from healthy subjects $(13,14)$. As revealed in Table I (13-31), 35 miRNAs were screened, which were reported in the last 5 years with a ROC (AUC) $>0.500$. For example, Momen-Heravi et al reported that upregulated miR-27b and downregulated miR-136 derived from the saliva were able to differentiate between patients with oral cancer and healthy subjects (15). The ROC (AUC) of miR-21 extracted from oral cytology and miR-99a from the serum were up to 0.910 (16) and 0.911 (17), respectively. Gombos et al reported that miR-155 derived from tissues was able to distinguish between patients with oral cancer and healthy individuals [ROC $(\mathrm{AUC})=0.925]$ (13). These data revealed that miRNAs originating from different samples may be considered as biomarkers for oral cancer diagnosis.

miRNAs as novel prognostic biomarkers in oral cancer. The expression profiles of certain miRNAs have demonstrated a positive correlation with clinical stage, metastasis and patient survival, indicating that these miRNAs may be considered as prognostic indices in oral cancer. Lai et al revealed that dysregulated miR-31-5p expression enhanced OSCC cell migration and invasion and accelerated oral cancer progression (32). In recent years, miRNAs have been reported to be strongly correlated with the survival of oral cancer patients. Chen et al indicated that patients with high expression level of miR-99a displayed a better prognosis and longer overall survival (17). Supic et al revealed that patients with miR-183 overexpression had markedly shorter overall survival and higher risk of poor outcome (23). Zheng et al reported that miR-503-5p, miR-450b-5p, miR-27a-3p, miR-181a-5p and miR-183-5p were overexpressed in patients with oral cancer, and they were all highly associated with cancer cell proliferation, advanced clinical stage and poor prognosis (33). Cheng et al revealed that the expression level of miR-455-5p was associated with the nodal status, stage and overall survival of the patients, suggesting that miR-455-5p may be a promising prognostic marker for predicting the outcome of patients with oral cancer (34). We herein also summarized other miRNAs that may be of prognostic value in oral cancer (Table II). All the aforementioned data indicated that miRNAs may be valuable prognostic indicators in oral cancer.

\section{Therapeutic effects of miRNAs in oral cancer}

miRNAs play a key role in regulating the translation or degradation of mRNAs by interacting with the 3 ' untranslated region (3'UTR) or coding region of mRNAs and regulating the expression level of their target genes (35). miRNAs are involved in the cellular processes of cancer, such as inflammation, proliferation, stress response, growth, apoptosis, survival and migration (10). Therefore, manipulating miRNA expression in cancer has been attracting increasing attention as a novel therapeutic strategy. It was reported that miR-24-3p, miR-155-5p and miRNA-10a may significantly promote the proliferation of oral cancer cells $(18,36,37)$. These findings suggested that silencing the expression of specific miRNAs may prevent the progression of oral cancer. Conversely, numerous miRNAs have been revealed to have an anticancer function. miR-6887-5p, miR-34a-5p and miR-142-3p markedly suppressed the proliferation of oral cancer cells (38-40). In addition, certain miRNAs, such as miR-204-5p and miR-34a-5p, exert their anticancer effects by inhibiting the aggressiveness and metastasis of oral cancer cells $(39,41)$. The targets and functional roles of miRNAs are listed in Table II (17-19,23,32,33,36-54).

Regulatory mechanism of miRNAs in oral cancer. miRNAs belong to a family of non-coding RNAs that play key roles in suppressing or promoting cancer by interacting with their target mRNAs. Several studies have demonstrated that miRNAs are involved in the occurrence, progression and metastasis of oral cancer (Fig. 1) $(53,55)$.

miRNAs and oral cancer occurrence and progression. Accumulating evidence indicates that miRNAs play a key role in the occurrence and progression of oral cancer. The protein kinase B (AKT) and mammalian target of rapamycin (mTOR) pathways are known to participate in the regulation of oral cancer occurrence (56). Manikandan et al revealed that $>40$ differentially expressed miRNAs in OSCC may activate the AKT pathway (57). miR-218 can inhibit the activation of mTOR/AKT pathway by targeting Rictor, and then suppress oral carcinogenesis (58). In oral cancer, miR-99 has been revealed to decreased the expression level of mTOR by directly binding with mTOR mRNA, thereby promoting cancer cell growth and increasing tumor size $(59,60)$. The expression level of miR-455-5p has been revealed to be regulated by the TGF- $\beta$-dependent pathway, which subsequently promotes oral tumorigenesis by downregulating ubiquitin-conjugating enzyme E2B (UBE2B) (34). Chen et al revealed that CD36 contributed to the proliferation and invasion of OSCC, and miR-1254 may inhibit the progression of OSCC by partially downregulating the expression level of CD36 (61). In addition, inhibiting the expression of miR-423-5p may rescue the carcinogenic effect of lncRNA CASC9 by silencing the expression of SRY-box transcription factor 12 (SOX12) (62). These data revealed that miRNAs participate in oral carcinogenesis and progression by regulating their target genes.

miRNAs and oral cancer cell proliferation and apoptosis. The proliferation and apoptosis of oral cancer cells are regulated by multiple factors, with an increasing number of studies demonstrating that miRNAs are involved in the regulation of these cellular process. Rastogi et al reported that in vitro restoration of miR-377 suppressed OSCC cell growth and induced apoptosis by regulating HDAC9 and its pro-apoptotic target, NR4A1/Nur77 (63). miR-23a-3p may suppress proliferation 
Table I. Sample source, expression level and ROC (AUC) of miRNAs in oral cancer.

\begin{tabular}{|c|c|c|c|c|c|}
\hline No. & miRNAs & Sample type & $\begin{array}{l}\text { Expression level in oral } \\
\text { cancer vs. normal sample }\end{array}$ & ROC (AUC) & (Refs.) \\
\hline 1 & miR-21 & Oral cytology & Upregulated & 0.910 & (16) \\
\hline 2 & $\operatorname{miR}-24-3 p$ & Saliva & Upregulated & 0.738 & (18) \\
\hline 3 & miR-31-5p & Serum & Upregulated & 0.661 & (19) \\
\hline 4 & miR-512-3p & Saliva & Upregulated & 0.847 & (20) \\
\hline 5 & $\operatorname{miR}-412-3 p$ & Saliva & Upregulated & 0.871 & (20) \\
\hline 6 & miR-222-3p & Plasma & Upregulated & 0.702 & (21) \\
\hline 7 & miR-150-5p & Plasma & Upregulated & 0.520 & (21) \\
\hline 8 & $\operatorname{miR}-423-5 p$ & Plasma & Upregulated & 0.677 & (21) \\
\hline 9 & miR-548b & Tissue & Upregulated & 0.651 & (22) \\
\hline 10 & miR-18a & Tissue & Upregulated & 0.682 & (22) \\
\hline 11 & miR-183 & Tissue & Upregulated & 0.700 & (23) \\
\hline 12 & miR-483-5p & Serum & Upregulated & 0.850 & (24) \\
\hline 13 & $\operatorname{miR}-125 b$ & Plasma & Upregulated & 0.966 & (25) \\
\hline 14 & miRNA-184 & Saliva & Upregulated & 0.860 & (26) \\
\hline 15 & miR-196a & Plasma & Upregulated & 0.864 & (27) \\
\hline 16 & miR-196b & Plasma & Upregulated & 0.960 & (27) \\
\hline 17 & miR-494 & Whole blood & Upregulated & 0.720 & (28) \\
\hline 18 & miR-3651 & Whole blood & Upregulated & 0.800 & (28) \\
\hline 19 & $\operatorname{miR}-27 b$ & Saliva & Upregulated & 0.964 & (15) \\
\hline 20 & miR-155 & Tissues & Upregulated & 0.925 & (13) \\
\hline 21 & miR-221 & Tissues & Upregulated & 0.901 & (13) \\
\hline 22 & miR-16 & Serum & Upregulated & 0.840 & (14) \\
\hline 23 & let-7b & Serum & Upregulated & 0.820 & (14) \\
\hline 24 & miR-3651 & Tissue & Downregulated & 0.779 & (29) \\
\hline 25 & miR-99a & Serum & Downregulated & 0.911 & (17) \\
\hline 26 & $\operatorname{miR}-542-3 p$ & Plasma & Downregulated & 0.820 & (30) \\
\hline 27 & miR-375 & Oral cytology & Downregulated & 0.910 & (16) \\
\hline 28 & miR-139-5p & Saliva & Downregulated & 0.805 & (31) \\
\hline 29 & miRNA-145 & Saliva & Downregulated & 0.680 & (26) \\
\hline 30 & miR-186 & Whole blood & Downregulated & 0.690 & (28) \\
\hline 31 & miR-136 & Saliva & Downregulated & 0.968 & (15) \\
\hline 32 & miR-191 & Tissues & Downregulated & 0.887 & (13) \\
\hline 33 & miR-333-3p & Serum & Downregulated & 0.820 & (14) \\
\hline 34 & miR-29a & Serum & Downregulated & 0.820 & (14) \\
\hline 35 & miR-223 & Serum & Downregulated & 0.810 & (14) \\
\hline
\end{tabular}

ROC, receiver operating characteristic; AUC, area under the curve.

and promote apoptosis of OSCC cells by targeting fibroblast growth factor 2 (FGF1) (64). By contrast, it was reported that miR-155 contributed to oral cancer cell proliferation, inhibited cell apoptosis and reduced the sensitivity of oral cancer cells to DDP by downregulating Foxo3a expression (65). Furthermore, miR-155 promoted cell cycle progression and cell proliferation and suppressed apoptosis by inhibiting p27 $7^{\mathrm{Kip} 1}$ expression (66).

miRNAs and oral cancer cell migration, invasion and metastasis. The migration, invasion and metastasis of oral cancer cells are highly associated with the therapeutic strategy. miRNAs are involved in the regulation of these processes in oral cancer cells. Fang et al reported that miR-204-5p suppressed oral cancer cell aggressiveness, viability and migration by targeting and inhibiting: Huntingtin-interacting protein 1 (HIP1) expression (41). Overexpression of miR-143 and miR-145 in OSCC cells markedly suppressed the expression of activin A, and suppressed the migration and invasion of oral cancer cells, prevented lymph node metastasis, increased tumor differentiation and prolonged the survival of the patients (67). Huang et al revealed that enhancing the expression of miR-491-5p significantly downregulated the expression of GPCR kinase 2 interacting protein 1 (GIT1), 
Table II. Targets and functional roles of miRNAs in oral cancer.

\begin{tabular}{|c|c|c|c|c|c|c|c|}
\hline \multirow[b]{2}{*}{ No. } & \multirow[b]{2}{*}{ miRNAs } & \multirow[b]{2}{*}{ Targets } & \multicolumn{4}{|c|}{ Pathoclinical appearances } & \multirow[b]{2}{*}{ (Refs.) } \\
\hline & & & $\begin{array}{l}\text { Metastatic } \\
\text { potential }\end{array}$ & $\begin{array}{l}\text { Growth } \\
\text { potential }\end{array}$ & $\begin{array}{l}\text { Invasive } \\
\text { status }\end{array}$ & $\begin{array}{l}\text { Prognosis } \\
\text { of patients }\end{array}$ & \\
\hline 1 & $\operatorname{miR}-24-3 p$ & PER1 & / & $\uparrow$ & / & / & $(18)$ \\
\hline 2 & miR-31-5p & ACOX1 & $\uparrow$ & $\uparrow$ & $\uparrow$ & l & $(19,32)$ \\
\hline 3 & miR-99a & l & l & l & l & $\uparrow$ & (17) \\
\hline 4 & $\operatorname{miR}-183$ & l & l & l & l & $\downarrow$ & (23) \\
\hline 5 & miR-204-5p & HIP1 & $\downarrow$ & $\downarrow$ & $\downarrow$ & / & $(41)$ \\
\hline 6 & miR-6887-5p & HBp17 & l & $\downarrow$ & l & / & $(38)$ \\
\hline 7 & miR-155-5p & ARID2 & $\uparrow$ & $\uparrow$ & $\uparrow$ & / & $(36)$ \\
\hline 8 & hsa-mir-99b-3p & l & / & / & l & $\uparrow$ & $(42)$ \\
\hline 9 & hsa-mir-100-5p & / & / & l & l & $\downarrow$ & (42) \\
\hline 10 & miRNA-10a & GLUT1 & l & $\uparrow$ & l & / & $(37)$ \\
\hline 11 & hsa-miR-let.7i-3p & l & l & l & l & $\uparrow$ & (43) \\
\hline 12 & miR-450a & TMEM182 & l & l & $\uparrow$ & / & (44) \\
\hline 13 & miR-29b-1-5p & CDH1 & l & / & 1 & $\downarrow$ & $(45)$ \\
\hline 14 & $\operatorname{miR}-210-3 p$ & RGMA & l & $\uparrow$ & l & / & $(46)$ \\
\hline 15 & $\operatorname{miR}-545$ & RIG-I & $\downarrow$ & $\downarrow$ & / & / & $(47)$ \\
\hline 16 & miR-21 & TNF- $\alpha$ & l & $\uparrow$ & / & l & $(48)$ \\
\hline 17 & $\begin{array}{l}\operatorname{miR}-503-5 p, \text { miR-450b-5p, miR-27a-3p } \\
\text { miR-181a-5p and miR-183-5p }\end{array}$ & $\mathrm{ROR} \alpha$ & l & $\uparrow$ & / & $\downarrow$ & (33) \\
\hline 18 & miR-211 & BIN1 & $\uparrow$ & $\uparrow$ & $\uparrow$ & / & (49) \\
\hline 19 & $\operatorname{miR}-34 a-5 p$ & AXL & $\downarrow$ & $\downarrow$ & l & l & (39) \\
\hline 20 & miR-134 & PDCD7 & $\uparrow$ & / & l & / & $(50)$ \\
\hline 21 & miR-203 & Bmi-1 & / & $\downarrow$ & 1 & / & $(51)$ \\
\hline 22 & miR-196a-5p & BIRC3 & l & $\downarrow$ & l & / & $(52)$ \\
\hline 23 & miR-30a-5p & FAP & $\downarrow$ & $\downarrow$ & $\downarrow$ & / & (53) \\
\hline 24 & miR-1246 & DENND2D & $\uparrow$ & I & $\uparrow$ & l & (54) \\
\hline 25 & miR-142-3p & TGFBR1 & $\downarrow$ & $\downarrow$ & $\downarrow$ & l & $(40)$ \\
\hline
\end{tabular}

$\uparrow$ : Indicates a promoting effect; $\downarrow$ : Indicates an inhibitory effect; /: Indicates an unknown effect. PER1, period 1 gene; ACOX1, acyl-CoA oxidase 1; HIP1, Huntingtin-interacting protein 1; HBp17, heparin-binding protein 17; ARID2, AT-rich interaction domain 2; GLUT1, glucose transporter 1; TMEM182, transmembrane protein 182; CDH1, E-cadherin gene 1; RGMA, repulsive guidance molecule A; RIG-I, retinoic acid-inducible gene-I; TNF- $\alpha$, tumor necrosis factor $\alpha$; ROR $\alpha$, retinoic acid receptor-related orphan receptor $\alpha$; BIN1, bridging integrator 1; AXL, receptor tyrosine kinase; PDCD7, programmed cell death 7; Bmi-1, B-cell-specific Moloney murine leukemia virus integration site 1; BIRC3, baculoviral IAP repeat-containing 3; FAP, fibroblast activation protein; DENND2D, differentially expressed in normal cells and neoplasia domain containing $2 \mathrm{D}$; TGFBR 1 , TGF- $\beta$ receptor 1 .

thereby suppressing OSCC cell migration in vitro and lung metastasis in vivo (68). Conversely, overexpression of miR-21 was associated with perineural invasion and worse prognosis in OSCC patients (69). Tu et al reported that overexpression of miR-372 and miR-373 were associated with nodal metastasis, lymph vascular invasion and poor survival by regulating the expression of large tumor suppressor kinase 2 (LATS2) in OSCC cells (70).

miRNAs as novel therapeutic tools in oral cancer. A large volume of evidence has demonstrated that miRNAs play key roles in oral cancer occurrence and growth, cancer cell migration and invasion, cancer progression and patient prognosis. This evidence suggests that miRNAs may be considered as novel therapeutic tools for oral cancer.
It was reported that upregulation of miR-375 markedly inhibited cell proliferation, induced cell cycle arrest in the G0/G1 phase, promoted apoptosis and increased radiosensitivity in OSCC cells, suggesting that miR-375 may be a potential therapeutic target for OSCC patients (71). miR-494-3p was able to enhance the radiosensitivity of OSCC cells by promoting cellular senescence (72). Min et al revealed that overexpression of miR-148a in cancer-associated fibroblasts significantly decreased the migration and invasion abilities of oral cancer cells by directly targeting WNT10B, suggesting that miR-148a may be a novel promising target for the treatment of OSCC (73). Chen et al reported that miR-1254 may inhibit the progression of OSCC, and restoring miR-1254 expression may represent an effective treatment strategy for 


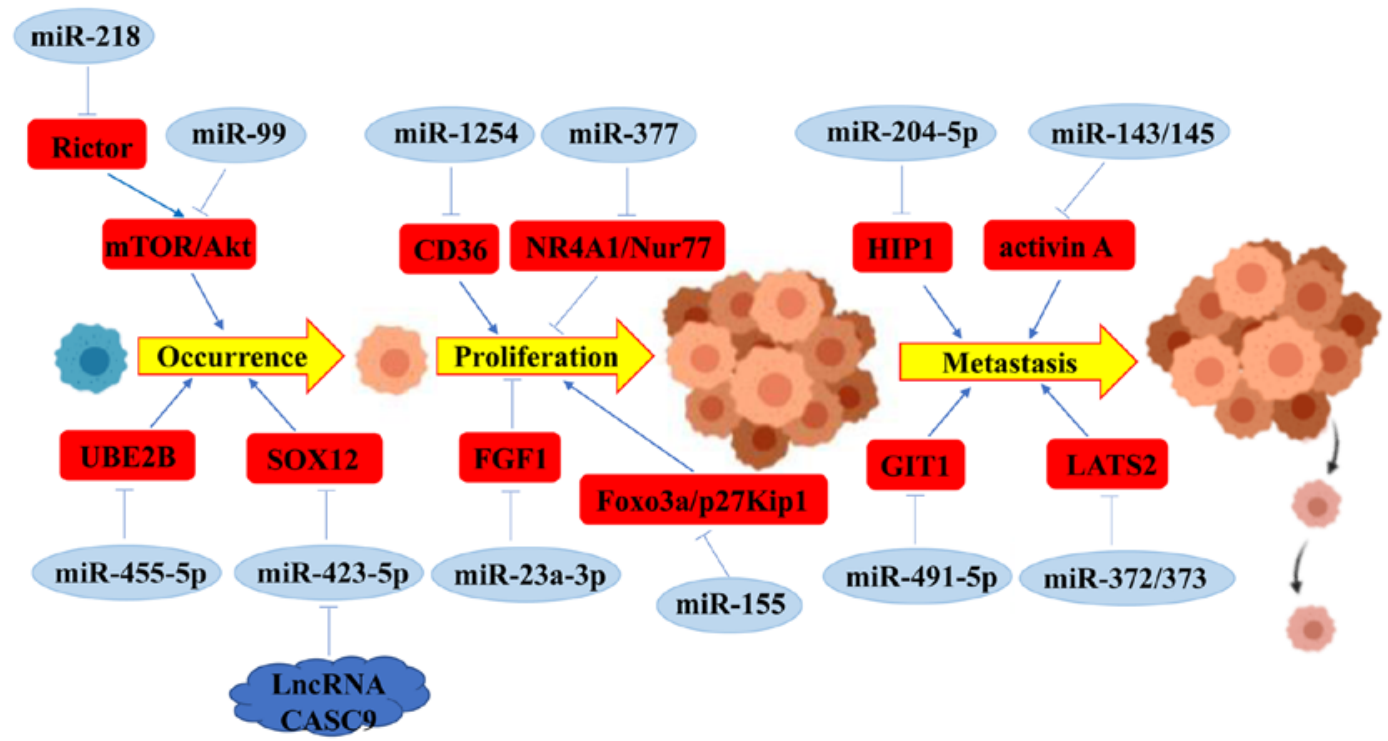

Figure 1. miRNAs involved in oral cancer progression. Summarized representation of miRNAs and their regulatory networks in oral cancer occurrence, proliferation and metastasis. mTOR, mammalian target of rapamycin; Akt, protein kinase B; UBE2B, ubiquitin-conjugating enzyme E2B; SOX12, SRY-box transcription factor 12; FGF1, fibroblast growth factor 2; NR4A1/Nur77, nuclear receptor subfamily 4 group A member 1; Foxo3a/p27 ${ }^{\text {Kip1 }}$, forkhead box O3A/cyclin-dependent kinase inhibitor 1B; HIP1, Huntingtin-interacting protein 1; GIT1, GPCR kinase 2 interacting protein 1; LATS2, large tumor suppressor kinase 2. $\uparrow$ : Promoting effect; T: Inhibiting effect. (This figure was created using BioRender.com).

OSCC (61). Similarly, miR-377 and miR-23a-3p suppressed cell proliferation and promoted apoptosis in OSCC, suggesting that both miR-377 and miR-23a-3p may prove to be of value as therapeutic targets for OSCC in the future $(63,64)$. In summary, all the aforementioned data suggest that miRNAs may be considered as effective anticancer targets, and they may be used to develop novel treatment strategies for oral cancer.

\section{Discussion and outlook}

Although great progress has been made in the diagnosis of oral cancer, the methods for early diagnosis and prognosis require further improvements. Early diagnosis may markedly increase the effectiveness of treatment and prolong the survival of patients with oral cancer. Therefore, it is urgent to develop novel biomarkers with higher accuracy, sensitivity and specificity, that are more convenient for clinical detection.

With the development of sequencing technology, an increasing number of miRNAs have been revealed to be specifically expressed in a variety of samples from oral cancer $(15,16)$. These miRNAs also play a key role in regulating cellular processes and behaviors $(66,68)$. miRNAs may represent optimal biomarkers and new therapeutic tools for oral cancer. However, although the miRNAs aforementioned appear to be promising candidates as biomarkers, they require further investigation, including biological study and clinical verification. Furthermore, the source, formation and regulatory networks of miRNAs are quite complex, and the expression level of miRNAs in different stages of oral cancer is also different. Hence, it is necessary to elucidate the mechanism of miRNA formation, which may contribute to early diagnosis, targeted therapy and prognosis evaluation of oral cancer patients. Notably, the therapeutic miRNAs that may be used to develop novel targeted drugs require further research in terms of suitable and effective in vivo delivery methods. Identifying key targets and building a targeted delivery system (such as a nano-miRNA system) will be our future research priorities.

\section{Acknowledgements}

Not applicable.

\section{Funding}

The present study was supported by the National Science Foundation of China (grant no. 81372908).

\section{Availability of data and materials}

All data generated or analyzed during this study are included in this published article.

\section{Authors' contributions}

JW, RY, JY designed the review and edited the manuscript. JW, NL, XL wrote the manuscript. JW, RY and ZC collected and analyzed data. All authors read and approved the final manuscript.

\section{Ethics approval and consent to participate}

Not applicable.

\section{Patient consent for publication}

Not applicable.

\section{Competing interests}

The authors declare that they have no competing interests. 


\section{References}

1. Santoro A, Pannone G, Papagerakis S, Serpico R and Bufo P: Epigenetic profiling of oral cancer. InTech: Mar 14, 2012 (Epub ahead of print). doi: 10.5772/31386.

2. Tsantoulis PK, Kastrinakis NG, Tourvas AD, Laskaris G and Gorgoulis VG: Advances in the biology of oral cancer. Oral Oncol 43: 523-534, 2007.

3. Gupta B, Johnson NW and Kumar N: Global epidemiology of head and neck cancers: A continuing challenge. Oncology 91: 13-23, 2016.

4. Bray F, Ferlay J, Soerjomataram I, Siegel RL, Torre LA and Jemal A: Global cancer statistics 2018: GLOBOCAN estimates of incidence and mortality worldwide for 36 cancers in 185 countries. CA Cancer J Clin 68: 394-424, 2018.

5. Huppi K, Volfovsky N, Mackiewicz M, Runfola T, Jones TL, Martin SE, Stephens R and Caplen NJ: MicroRNAs and genomic instability. Semin Cancer Biol 17: 65-73, 2007.

6. Mitchell PS, Parkin RK, Kroh EM, Fritz BR, Wyman SK, Pogosova-Agadjanyan EL, Peterson A, Noteboom J, O'Briant KC Allen A, et al: Circulating microRNAs as stable blood-based markers for cancer detection. Proc Natl Acad Sci USA 105: 10513-10518, 2008.

7. Chawla JP, Iyer N, Soodan KS, Sharma A, Khurana SK and Priyadarshni P: Role of miRNA in cancer diagnosis, prognosis, therapy and regulation of its expression by Epstein-Barr virus and human papillomaviruses: With special reference to oral cancer. Oral Oncol 51: 731-737, 2015.

8. Chen X, Ba Y, Ma L, Cai X, Yin Y, Wang K, Guo J, Zhang Y, Chen J, Guo X, et al: Characterization of microRNAs in serum: A novel class of biomarkers for diagnosis of cancer and other diseases. Cell Res 18: 997-1006, 2008.

9. Croce CM and Calin GA: miRNAs, cancer, and stem cell division. Cell 122: 6-7, 2005.

10. Di Leva G, Garofalo M and Croce CM: MicroRNAs in cancer Annu Rev Pathol 9: 287-314, 2014.

11. Fabbri M: MicroRNAs and cancer: Towards a personalized medicine. Curr Mol Med 13: 751-756, 2013.

12. Madhura MG,RaoRS,PatilS,Fageeh HN,Alhazmi A and AwanKH: Advanced diagnostic aids for oral cancer. Dis Mon: Jun 25, 2020 (Epub ahead of print). doi: 10.1016/j.disamonth.2020.101034.

13. Gombos K, Horváth R, Szele E, Juhász K, Gocze K, Somlai K, Pajkos G, Ember I and Olasz L: miRNA expression profiles of ora squamous cell carcinomas. Anticancer Res 33: 1511-1517, 2013.

14. Maclellan SA, Lawson J, Baik J, Guillaud M, Poh CF and Garnis C: Differential expression of miRNAs in the serum of patients with high-risk oral lesions. Cancer Med 1: 268-274, 2012.

15. Momen-Heravi F, Trachtenberg AJ, Kuo WP and Cheng YS Genomewide study of salivary MicroRNAs for detection of oral cancer. J Dent Res 93 (Suppl 7): 86S-93S, 2014.

16. He Q, Chen Z, Cabay RJ, Zhang L, Luan X, Chen D, Yu T, Wang $A$ and Zhou X: microRNA-21 and microRNA-375 from oral cytology as biomarkers for oral tongue cancer detection. Oral Oncol 57: 15-20, 2016.

17. Chen L, Hu J, Pan L, Yin X, Wang Q and Chen H: Diagnostic and prognostic value of serum miR-99a expression in oral squamous cell carcinoma. Cancer Biomark 23: 333-339, 2018.

18. He L, Ping F, Fan Z, Zhang C, Deng M, Cheng B and Xia J: Salivary exosomal miR-24-3p serves as a potential detective biomarker for oral squamous cell carcinoma screening. Biomed Pharmacother 121: 109553, 2020.

19. Lu Z, He Q, Liang J, Li W, Su Q, Chen Z, Wan Q, Zhou X, Cao L, Sun J, et al: miR-31-5p is a potential circulating biomarker and therapeutic target for oral cancer. Mol Ther Nucleic Acids 16: $471-480,2019$

20. Gai C, Camussi F, Broccoletti R, Gambino A, Cabras M, Molinaro L, Carossa S, Camussi G and Arduino PG: Salivary extracellular vesicle-associated miRNAs as potential biomarkers in oral squamous cell carcinoma. BMC Cancer 18: 439, 2018

21. Chang YA, Weng SL, Yang SF, Chou CH, Huang WC Tu SJ, Chang TH, Huang CN, Jong YJ and Huang HD: A Three-MicroRNA signature as a potential biomarker for the early detection of oral cancer. Int J Mol Sci 19: 758, 2018.

22. Berania I, Cardin GB, Clément I, Guertin L, Ayad T, Bissada E, Nguyen-Tan PF, Filion E, Guilmette J, Gologan O, et al: Four PTEN-targeting co-expressed miRNAs and ACTN4-targeting miR-548b are independent prognostic biomarkers in human squamous cell carcinoma of the oral tongue. Int J Cancer 141: 2318-2328, 2017
23. Supic G, Zeljic K, Rankov AD, Kozomara R, Nikolic A, Radojkovic D and Magic Z: miR-183 and miR-21 expression as biomarkers of progression and survival in tongue carcinoma patients. Clin Oral Investig 22: 401-409, 2018.

24. Xu H, Yang Y, Zhao H, Yang X, Luo Y, Ren Y, Liu W and Li N: Serum miR-483-5p: A novel diagnostic and prognostic biomarker for patients with oral squamous cell carcinoma. Tumour Biol 37: 447-453, 2016

25. Gu WL, Ye DX and Wu JJ: Expression and clinical significance of plasma microRNA-125b level in patients with oral squamous cell carcinoma. Shanghai Kou Qiang Yi Xue 24: 71-75, 2015 (In Chinese).

26. Zahran F, Ghalwash D, Shaker O, Al-Johani K and Scully C: Salivary microRNAs in oral cancer. Oral Dis 21: 739-747, 2015.

27. Lu YC, Chang JT, Huang YC, Huang CC, Chen WH, Lee LY, Huang BS, Chen YJ, Li HF and Cheng AJ: Combined determination of circulating miR-196a and miR-196b levels produces high sensitivity and specificity for early detection of oral cancer. Clin Biochem 48: 115-121, 2015.

28. Ries J, Vairaktaris E, Kintopp R, Baran C, Neukam FW and Nkenke E: Alterations in miRNA expression patterns in whole blood of OSCC patients. In Vivo 28: 851-861, 2014

29. Ries J, Baran C, Wehrhan F, Weber M, Motel C, Kesting M and Nkenke E: The altered expression levels of miR-186, miR-494 and miR-3651 in OSCC tissue vary from those of the whole blood of OSCC patients. Cancer Biomark 24: 19-30, 2019.

30. Wu N, Lu Y and Liang JZ: Expression and correlation of survivin and hsa-miR-542-3p in patients with oral squamous cell carcinoma. Shanghai Kou Qiang Yi Xue 25: 720-724, 2016 (In Chinese).

31. Duz MB, Karatas OF, Guzel E, Turgut NF, Yilmaz M, Creighton CJ and Ozen M: Identification of miR-139-5p as a saliva biomarker for tongue squamous cell carcinoma: A pilot study. Cell Oncol (Dordr) 39: 187-193, 2016.

32. Lai YH, Liu H, Chiang WF, Chen TW, Chu LJ, Yu JS, Chen SJ, Chen HC and Tan BC: MiR-31-5p-ACOX1 Axis enhances tumorigenic fitness in oral squamous cell carcinoma via the promigratory prostaglandin E2. Theranostics 8: 486-504, 2018.

33. Zheng X, Wu K, Liao S, Pan Y, Sun Y, Chen X, Zhang Y, Xia S, $\mathrm{Hu} \mathrm{Y}$ and Zhang J: MicroRNA-transcription factor network analysis reveals miRNAs cooperatively suppress RORA in oral squamous cell carcinoma. Oncogenesis 7: 79, 2018.

34. Cheng CM, Shiah SG, Huang CC, Hsiao JR and Chang JY: Up-regulation of miR-455-5p by the TGF- $\beta$-SMAD signalling axis promotes the proliferation of oral squamous cancer cells by targeting UBE2B. J Pathol 240: 38-49, 2016.

35. Agarwal V, Bell GW, Nam JW and Bartel DP: Predicting effective microRNA target sites in mammalian mRNAs. Elife 4: $\mathrm{e} 05005,2015$

36. Wu M, Duan Q, Liu X, Zhang P, Fu Y, Zhang Z, Liu L, Cheng J and Jiang H: MiR-155-5p promotes oral cancer progression by targeting chromatin remodeling gene ARID2. Biomed Pharmacother 122: 109696, 2020.

37. Chen YH, Song Y, Yu YL, Cheng W and Tong X: miRNA-10a promotes cancer cell proliferation in oral squamous cell carcinoma by upregulating GLUT1 and promoting glucose metabolism. Oncol Lett 17: 5441-5446, 2019.

38. Higaki M, Shintani T, Hamada A, Rosli SNZ and Okamoto T: Eldecalcitol (ED-71)-induced exosomal miR-6887-5p suppresses squamous cell carcinoma cell growth by targeting heparin-binding protein 17/fibroblast growth factor-binding protein-1 (HBp17/FGFBP-1). In vitro cellular \& developmental biology. In Vitro Cell Dev Biol Anim 56: 222-233, 2020.

39. Li YY, Tao YW, Gao S, Li P, Zheng JM, Zhang SE, Liang J and Zhang Y: Cancer-associated fibroblasts contribute to oral cancer cells proliferation and metastasis via exosome-mediated paracrine miR-34a-5p. EBioMedicine 36: 209-220, 2018.

40. Dickman CT, Lawson J, Jabalee J, MacLellan SA, LePard NE, Bennewith KL and Garnis C: Selective extracellular vesicle exclusion of miR-142-3p by oral cancer cells promotes both internal and extracellular malignant phenotypes. Oncotarget 8 : 15252-15266, 2017.

41. Fang $\mathrm{X}$, Tang $\mathrm{Z}$, Zhang $\mathrm{H}$ and Quan $\mathrm{H}$ : Long non-coding RNA DNM3OS/miR-204-5p/HIP1 axis modulates oral cancer cell viability and migration. J Oral Pathol Med 49: 865-875, 2020

42. Jakob M, Mattes LM, Küffer S, Unger K, Hess J, Bertlich M, Haubner F, Ihler F, Canis M, Weiss BG and Kitz J: MicroRNA expression patterns in oral squamous cell carcinoma: hsa-mir-99b-3p and hsa-mir-100-5p as novel prognostic markers for oral cancer. Head Neck 41: 3499-3515, 2019. 
43. Falzone L, Lupo G, La Rosa GR, Crimi S, Anfuso CD, Salemi R, Rapisarda E, Libra M and Candido S: Identification of Novel MicroRNAs and their diagnostic and prognostic significance in oral cancer. Cancers 11: 610, 2019.

44. Hsing EW, Shiah SG, Peng HY, Chen YW, Chuu CP, Hsiao JR, Lyu PC and Chang JY: TNF- $\alpha$-induced miR-450a mediates TMEM182 expression to promote oral squamous cell carcinoma motility. PLoS One 14: e0213463, 2019.

45. Kurihara-Shimomura M,Sasahira T, Shimomura H,Nakashima $C$ and Kirita T: miR-29b-1-5p the oncogenic activity of induces the epithelial-mesenchymal transition in oral squamous cell carcinoma. J Clin Med 24: 273, 2019.

46. Lu Y, Li Y, Wang Z, Xie S, Wang Q, Lei X, Ruan Y and Li J: Downregulation of RGMA by HIF-1A/miR-210-3p axis promotes cell proliferation in oral squamous cell carcinoma. Biomed Pharmacother 112: 108608, 2019.

47. Yuan G, Wu H, Du Y and He F: Tumor suppressor role of microRNA-545 in oral squamous cell carcinoma. Oncol Lett 17: 2063-2068, 2019.

48. Qiu YF, Wang MX, Meng LN, Zhang R and Wang W: MiR-21 regulates proliferation and apoptosis of oral cancer cells through TNF- $\alpha$. Eur Rev Med Pharmacol Sci 22: 7735-7741, 2018.

49. Zheng J, Wang J, Jia Y, Liu T, Duan Y, Liang X and Liu L: microRNA-211 promotes proliferation, migration, and invasion ability of oral squamous cell carcinoma cells via targeting the bridging integrator 1 protein. J Cell Biochem 120: 4644-4653, 2019.

50. Peng SY, Tu HF, Yang CC, Wu CH, Liu CJ, Chang KW and Lin SC: miR-134 targets PDCD7 to reduce E-cadherin expression and enhance oral cancer progression. Int J Cancer 143: 2892-2904, 2018.

51. Kim JS, Choi DW, Kim CS, Yu SK, Kim HJ, Go DS, Lee SA, Moon SM, Kim SG, Chun HS, et al: MicroRNA-203 induces apoptosis by targeting in YD-38 oral cancer cells. Anticancer Res 38: 3477-3485, 2018

52. Wang L, Wei Y, Yan Y, Wang H, Yang J, Zheng Z, Zha J, Bo P, Tang Y, Guo X, et al: CircDOCK1 suppresses cell apoptosis via inhibition of miR-196a-5p by targeting BIRC 3 in OSCC. Oncol Rep 39: 951-966, 2018.

53. Ruan P, Tao Z and Tan A: Low expression of miR-30a-5p induced the proliferation and invasion of oral cancer via promoting the expression of FAP. Biosci Rep 38: BSR20171027, 2018.

54. Sakha S, Muramatsu T, Ueda K and Inazawa J: Exosomal microRNA miR-1246 induces cell motility and invasion through the regulation of DENND2D in oral squamous cell carcinoma. Sci Rep 6: 38750, 2016

55. Chuerduangphui J, Ekalaksananan T, Chaiyarit $P$, Patarapadungkit N, Chotiyano A, Kongyingyoes B, Promthet S and Pientong $\mathrm{C}$ : Effects of arecoline on proliferation of oral squamous cell carcinoma cells by dysregulating c-Myc and miR-22, directly targeting oncostatin M.PLoS One 13: e0192009, 2018.

56. Harsha C, Banik K, Ang HL, Girisa S, Vikkurthi R, Parama D, Rana V,ShabnamB,KhatoonE,Kumar APand KunnumakkaraAB: Targeting AKT/mTOR in oral cancer: Mechanisms and advances in clinical trials. Int J Mol Sci 21: 3285, 2020

57. Manikandan M, Deva Magendhra Rao AK, Arunkumar G, Manickavasagam M, Rajkumar KS, Rajaraman R and Munirajan AK: Oral squamous cell carcinoma: microRNA expression profiling and integrative analyses for elucidation of tumourigenesis mechanism. Mol Cancer 15: 28, 2016

58. Uesugi A, Kozaki K, Tsuruta T, Furuta M, Morita K, Imoto I, Omura $\mathrm{K}$ and Inazawa $\mathrm{J}$ : The tumor suppressive microRNA miR-218 targets the mTOR component Rictor and inhibits AKT phosphorylation in oral cancer. Cancer Res 71: 5765-5778, 2011.

59. Moratin J, Hartmann S, Brands R, Brisam M, Mutzbauer G, Scholz C, Seher A, Müller-Richter U, Kübler AC and Linz C: Evaluation of miRNA-expression and clinical tumour parameters in oral squamous cell carcinoma (OSCC). J Craniomaxillofac Surg 44: 876-881, 2016.
60. Chen D, Chen Z, Jin Y, Dragas D, Zhang L, Adjei BS, Wang A, Dai Y and Zhou X: MicroRNA-99 family members suppress Homeobox A1 expression in epithelial cells. PLoS One 8: e80625, 2013

61. Chen R, Zhang Y and Zhang X: MiR-1254 functions as a tumor suppressor in oral squamous cell carcinoma by targeting CD36. Technol Cancer Res Treat: Aug 11, 2019. doi: $10.1177 / 1533033819859447$.

62. Chen X, Xu H, Sun G and Zhang Y: LncRNA CASC9 affects cell proliferation, migration, and invasion of tongue squamous cell carcinoma via regulating miR-423-5p/SOX12 Axes. Cancer Manage Res 12: 277-287, 2020.

63. Rastogi B, Kumar A, Raut SK, Panda NK, Rattan V, Joshi N and Khullar M: Downregulation of miR-377 promotes oral squamous cell carcinoma growth and migration by targeting HDAC9. Cancer Invest 35: 152-162, 2017.

64. Chen F, Qi S, Zhang X, Wu J, Yang X and Wang R: miR-23a-3p suppresses cell proliferation in oral squamous cell carcinomas by targeting FGF2 and correlates with a better prognosis: miR-23a-3p inhibits OSCC growth by targeting FGF2. Pathol Res Pract 215: 660-667, 2019.

65. Li X, Liu K, Zhou W and Jiang Z: MiR-155 targeting FoxO3a regulates oral cancer cell proliferation, apoptosis, and DDP resistance through targeting FoxO3a. Cancer Biomark 27: 105-111, 2020.

66. Fu S, Chen $\mathrm{HH}$, Cheng P, Zhang CB and Wu Y: MiR-155 regulates oral squamous cell carcinoma Tca8113 cell proliferation, cycle, and apoptosis via regulating p27Kip1. Eur Rev Med Pharmacol Sci 21: 937-944, 2017

67. Bufalino A, Cervigne NK, de Oliveira CE, Fonseca FP, Rodrigues PC, Macedo CC, Sobral LM, Miguel MC, Lopes MA, Paes Leme AF, et al: Low miR-143/miR-145 cluster levels induce activin A overexpression in oral squamous cell carcinomas, which contributes to poor prognosis. PLoS One 10: e0136599, 2015.

68. Huang WC, Chan SH, Jang TH, Chang JW, Ko YC, Yen TC, Chiang SL, Chiang WF, Shieh TY, Liao CT, et al: miRNA-491-5p and GIT1 serve as modulators and biomarkers for oral squamous cell carcinoma invasion and metastasis. Cancer Res 74: 751-764, 2014.

69. Yu EH, Tu HF, Wu CH, Yang CC and Chang KW: MicroRNA-21 promotes perineural invasion and impacts survival in patients with oral carcinoma. J Chin Med Assoc 80: 383-388, 2017.

70. Tu HF, Chang KW, Cheng HW and Liu CJ: Upregulation of miR-372 and -373 associates with lymph node metastasis and poor prognosis of oral carcinomas. Laryngoscope 125: E365-E370, 2015.

71. Zhang B, Li Y, Hou D, Shi Q, Yang S and Li Q: MicroRNA-375 inhibits growth and enhances radiosensitivity in oral squamous cell carcinoma by targeting insulin like growth factor 1 receptor. Cell Physiol Biochem 42: 2105-2117, 2017.

72. Weng JH, Yu CC, Lee YC, Lin CW, Chang WW and Kuo YL: miR-494-3p induces cellular senescence and enhances radiosensitivity in human oral squamous carcinoma cells. Int J Mol Sci 17: 1092, 2016.

73. Min A, Zhu C, Peng S, Shuai C, Sun L, Han Y, Qian Y, Gao S and Su T: Downregulation of Microrna-148a in cancer-associated fibroblasts from oral cancer promotes cancer cell migration and invasion by targeting Wnt10b. J Biochem Mol Toxicol 30: 186-191, 2016.

This work is licensed under a Creative Commons Attribution-NonCommercial-NoDerivatives 4.0 International (CC BY-NC-ND 4.0) License. 